\title{
АНАЛІЗ МЕТОДУ УПРАВЛІННЯ СОНЯЧНИМ ВИПРОМІНЮВАННЯМ 3 ВИКОРИСТАННЯМ ОРБІТАЛЬНИХ ДЗЕРКАЛ
}

Проведено аналіз методу управління сонячним випромінюванням 3 використанням орбітальних дзеркал. Під час аналізу було визначено площу орбітальних дзеркал, необхідну для компенсації глобального потепління і повернення середньої температури поверхні Землі до доіндустріального рівня. Знайдено динаміку температури поверхні Землі при використанні методу управління сонячним випромінюванням 3 використанням орбітальних дзеркал.

Ключові слова: глобальне потепління, методи управління сонячним випромінюванням, орбітальні дзеркала, модель енергетичного балансу Землі.

\author{
D.V. Krasnoshapka, K.Y. Zolotko \\ Oles Honchar Dnipro National University
}

\section{SPACE-BASED METHOD OF SOLAR CLIMATE INTERVENTION ANALYSIS}

The analysis of a method of control of solar radiation with use of orbital mirrors is carried out. Potential methods of solar radiation control include the introduction of stratospheric aerosol injection, marine cloud brightening, cirrus cloud thinning, surface albedo modification, and so-called orbital mirrors or space-based methods for short.

An extremely promising approach to the possibility of reducing the global temperature of the Earth is the so-called control of solar radiation (solar climate intervention or solar radiation modification). This is an approach designed to mitigate the effects of climate change by reducing the amount of solar energy captured by the Earth's system. It should be noted that this approach is not self-sufficient, but should be used in conjunction with the reduction of greenhouse gas emissions, primarily $\mathrm{CO}^{2}$. Although the use of mirrors placed in space is considered by most researchers to be too expensive, as the cost of delivering cargo into orbit decreases, space methods can compete with terrestrial ones.

The analysis determined the area of orbital mirrors needed to compensate for global warming and return the average temperature of the Earth's surface to pre-industrial levels. To determine the total area of orbital mirrors, the equilibrium solution of the Earth's energy balance equation was used. The dynamics of the Earth's surface temperature using the method of controlling solar radiation using orbital mirrors is found.

It is determined that to achieve the global average surface temperature of the Earth to the pre-industrial level it is necessary to bring into orbit mirrors with a total area of about $3.23 * 10^{-12} \mathrm{~m}^{2}$.

The time at which the temperature of the Earth's surface becomes balanced after the onset of orbital mirrors is calculated. We use the equation of the model of energy balance of the Earth to determine the time to reach equilibrium temperature. This time is about $\mathbf{1 5}$ days and is quite small compared to the time of placement in orbit of all necessary mirrors.

\section{Красношапка Д.В., Золотько К.С., 2021}


Further research can be conducted to analyze the possible use of this method of controlling solar radiation in conjunction with other methods of reducing the global temperature of the Earth.

Key words: global warming, solar climate intervention, orbital mirrors, energy balance models.

\author{
Д.В. Красношапка, К.Е. Золотько \\ Днипровский национальный университет имени Олеся Гончара
}

\title{
АНАЛИЗ МЕТОДА УПРАВЛЕНИЯ СОЛНЕЧНЫМ ИЗЛУЧЕНИЕМ С ИСПОЛЬЗОВАНИЕМ ОРБИТАЛЬНЫХ ЗЕРКАЛ
}

Проведен анализ метода управления солнечным излучением с использованием орбитальных зеркал. При анализе была определена площадь орбитальных зеркал, необходимая для компенсации глобального потепления и возвращения средней температуры поверхности Земли до доиндустриального уровня. Найдена динамика температуры поверхности Земли при использовании метода управления солнечным излучением с использованием орбитальных зеркал.

Ключевые слова: глобальное потепление, методы управления солнечным излучением, орбитальные зеркала, модель энергетического баланса Земли.

Вступ. Вирішення проблеми глобального потепління стало критично важливим для виживання людства у середньостроковій перспективі. Глобальне потепління на $1^{\circ} \mathrm{C}$ порівняно $з$ доіндустріальним рівнем уже призвело до таких негативних наслідків як екстремальні погодні умови, підняття рівня океану та ін. Згідно зі спеціальним звітом міжурядової групи експертів з питань змін клімату (Intergovernmental Panel on Climate Change, IPCC) «Глобальне потепління на $1,5^{\circ} \mathrm{C} »$, зробленому у 2018 році, обмеження глобального потепління на рівні 1,5 градуса вимагає «безпрецедентних оперативних і масштабних змін у всіх сферах життя» [1]. У звіті запропоновано обмежити потепління на рівні $1,5^{\circ} \mathrm{C}$ шляхом скорочення глобальних викидів діоксиду вуглецю $\left(\mathrm{CO}_{2}\right)$ на $45 \%$ до 2030 року порівняно з 2010 роком і зведення їх до нуля до 2050 року. Очевидно досягти цієї амбітної мети не вдасться з огляду на надзвичайно високу вартість та недостатнє усвідомлення важливості даної проблеми урядами держав [2], тому дуже важливо розглянути альтернативні заходи.

Надзвичайно перспективним підходом до можливості зниження глобальної температури Землі є так зване управління сонячним випромінюванням (solar climate intervention або solar radiation modification) [3]. Це підхід, призначений для пом'якшення наслідків зміни клімату шляхом зменшення кількості сонячної енергії, яку захоплює система Землі. Треба зазначити, що даний підхід не є самодостатнім, а повинен використовуватися разом із скороченням викидів парникових газів, у першу чергу $\mathrm{CO}_{2}$.

Потенційні методи управління сонячним випромінюванням включають введення стратосферного аерозолю (stratospheric aerosol injection), освітлення хмар над морями (marine cloud brightening), проріджування перистих хмар 
(cirrus cloud thinning), модифікацію альбедо поверхонь (surface albedo modification) та, так звані, методи з використанням орбітальних дзеркал або скорочено - космічні методи (space-based methods).

Хоча використання дзеркал, розміщених у космосі, більшість дослідників вважають занадто дорогим [4], у міру здешевлення вартості доставлення вантажу на орбіту космічні методи можуть скласти конкуренцію наземним.

Постановка задачі. Розглянемо модель енергетичного балансу Землі [5]:

$$
C_{E} \frac{\partial T_{s}}{\partial t}=\left(1-\alpha_{p}\right) \frac{S_{0}}{4}-A \uparrow,
$$

де $C_{E}$ - ефективна теплоємність середовища (вимірюється у Дж/ $\left./ \mathrm{M}^{-2} \mathrm{~K}^{-1}\right), T_{s}$ температура поверхні, $t$ - час, $\alpha_{p}$ - альбедо планети, $S_{0}$ - сонячна стала і $A \uparrow$ - загальна кількість енергії, що випромінює $1 \mathrm{~m}^{2}$ поверхні Землі. $A \uparrow$ може бути представлена за законом Стефана-Больцмана, з використанням фактору $\tau$ для опису інфрачервоної проникності атмосфери, включаючи парниковий ефект:

$$
A \uparrow=\varepsilon \sigma T_{s}^{4} \tau,
$$

де $\sigma$ - стала Стефана-Больцмана, $\varepsilon$ - випромінювальна здатність поверхні.

Отже модель енергетичного балансу Землі представляється у вигляді відношення:

$$
C_{E} \frac{\partial T_{s}}{\partial t}=\left(1-\alpha_{p}\right) \frac{S_{0}}{4}-\varepsilon \sigma T_{s}^{4} \tau
$$

Метою даної роботи є, використовуючи дану модель, визначити:

- яка площа орбітальних дзеркал необхідна для компенсації глобального потепління;

- яка динаміка температури Землі для різних сценаріїв використання орбітальних дзеркал і темпів викидів парникових газів.

Визначення площі орбітальних дзеркал. Для визначення загальної площі орбітальних дзеркал можна використати рівноважне рішення рівняння енергетичного балансу Землі. Розглянемо ситуацію, коли кількість енергії, що приходить на Землю від Сонця дорівнює кількості енергії, що випромінюється Землею у космічний простір. Тоді $\frac{\partial T}{\partial t}=0$ і рівноважна температура Землі:

$$
T^{*}=\sqrt[4]{\frac{S_{0}\left(1-\alpha_{p}\right)}{4 \varepsilon \sigma \tau}}
$$

Використовуючи сонячну сталу $S_{0}=1362 \mathrm{BT} / \mathrm{M}^{2}$, альбедо $\alpha_{p}=0.3$, випромінювальну здатність поверхні $\varepsilon=0.97$ і значення $\tau=0.64$, маємо рівноважну температуру $286.86 \mathrm{~K}$, яка близька до реальної глобальної середньої температури.

Для розрахунку площі орбітальних дзеркал треба визначити на скільки з їх використанням треба зменшити потужність сонячного випромінювання. 
Із рівняння (3) можна визначити потужність сонячного випромінювання:

$$
S_{0}=\frac{4 \varepsilon \sigma T^{4} \tau}{1-\alpha_{p}}
$$

Нехай необхідно знизити глобальну середню температуру до доіндустріального рівня, тобто на $T_{2}^{*}-T_{1}^{*}$, де $T_{1}^{*}$ - поточна глобальна середня температура, $T_{2}^{*}$ - глобальна середня температура доіндустріального рівня. Згідно iз рівнянням (4) для цього треба зменшити потужність сонячного випромінювання на:

$$
S_{0_{2}}-S_{0_{1}}=\frac{4 \varepsilon \sigma \tau}{1-\alpha_{p}}\left(T_{2}^{* 4}-T_{1}^{* 4}\right),
$$

де $S_{0_{1}}$ - потужність сонячного випромінювання без використання дзеркал, a $S_{0_{2}}$ - потужність сонячного випромінювання з використанням дзеркал.

Якщо прийняти поточну глобальну середню температуру $15.4^{\circ} \mathrm{C}$ [6], тобто $T_{1}^{*}=288.4 \mathrm{~K}$ і факт того, що глобальне потепління призвело до підняття глобальної середньої температури на $1^{\circ}$, то маємо $S_{0_{2}}-S_{0_{1}}=-19.2 \mathrm{BT} / \mathrm{m}^{2}$, або у відносній величині $A=\frac{S_{0_{2}}-S_{0_{1}}}{S_{0}}=0.0141$, або $1.41 \%$.

Площу орбітальних дзеркал можна знайти таким чином:

$$
S_{m}=\frac{\pi R_{E}^{2} A}{n},
$$

де $R_{E}$ - радіус Землі, $\mathrm{n}$ - величина, яка показує яку частину довжини орбіти дзеркало відкидає тінь на Землю.

Величину $\mathrm{n}$ можна знайти із відношення довжини дуги $\mathrm{AB}$ до довжини орбіти дзеркала (див. рис. 1).

Довжина дуги АВ:

$$
L_{A B}=R_{o} \alpha,
$$

де $R_{o}$ - радіус орбіти дзеркала, $\alpha$ - центральний кут дуги АВ.

Довжина хорди AB:

$$
m_{A B}=2 R_{o} \sin \frac{\alpha}{2}
$$

3 виразів (6) i (7) величина n:

$$
n=\frac{L_{A B}}{C_{o}}=\frac{2 R_{o} \arcsin \frac{R_{E}}{R_{o}}}{2 \pi R_{o}}=\frac{1}{\pi} \arcsin \frac{R_{E}}{R_{o}}
$$

Для висоти орбіти дзеркал $\mathrm{R}_{\mathrm{o}}=400$ км величина $\mathrm{n}=0.39$. 


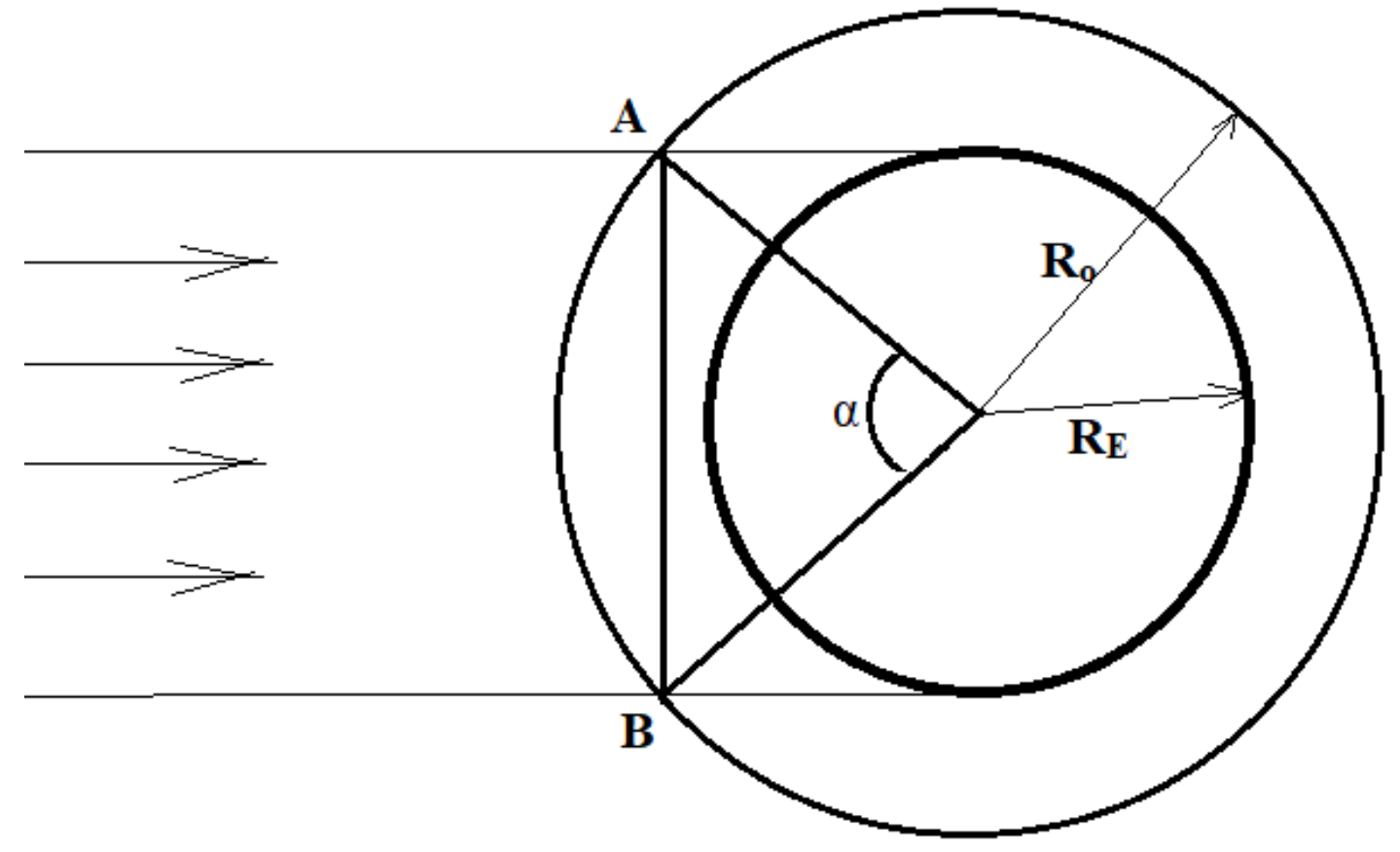

Рис. 1. До визначення частини довжини орбіти , на якій дзеркало відкидає тінь на Землю

Таким чином площа орбітальних дзеркал необхідна для компенсації глобального потепління і зниження глобальної середньої температури до доіндустріального рівня $S_{m}=3.23 \cdot 10^{12} \mathrm{~m}^{2}$ за умови якщо альбедо дзеркал дорівнює 1 і дзеркала орієнтовані перпендикулярно сонячним променям.

Визначення динаміки температури Землі при використанні орбітальних дзеркал. Очевидно, що якщо використовується метод управління сонячним випромінюванням шляхом розміщення орбітальних дзеркал рівноважна температура Землі установлюється не миттєво. Через велике значення теплоємності середовища поверхні суші і океану від моменту розміщення дзеркала на орбіті до моменту досягнення результату повинен проходити певний час. Представляє інтерес знайти цей час і оцінити чи не занадто довго температура системи буде врівноважуватися.

Для визначення часу досягнення рівноважної температури скористаємось рівнянням моделі енергетичного балансу Землі у формі (2).

Якщо взяти величину ефективної теплоємності середовища $C_{E}=2.08 \cdot 10^{8}$ Дж/м ${ }^{-2} \mathrm{~K}^{-1}[7]$, то залежність температури поверхні Землі від часу представляє собою криву, зображену на рис. 2 .

Дана залежність показує, що для досягнення рівноважної температури поверхні Землі від моменту розміщення дзеркал на орбіті проходить близько 15 діб. 


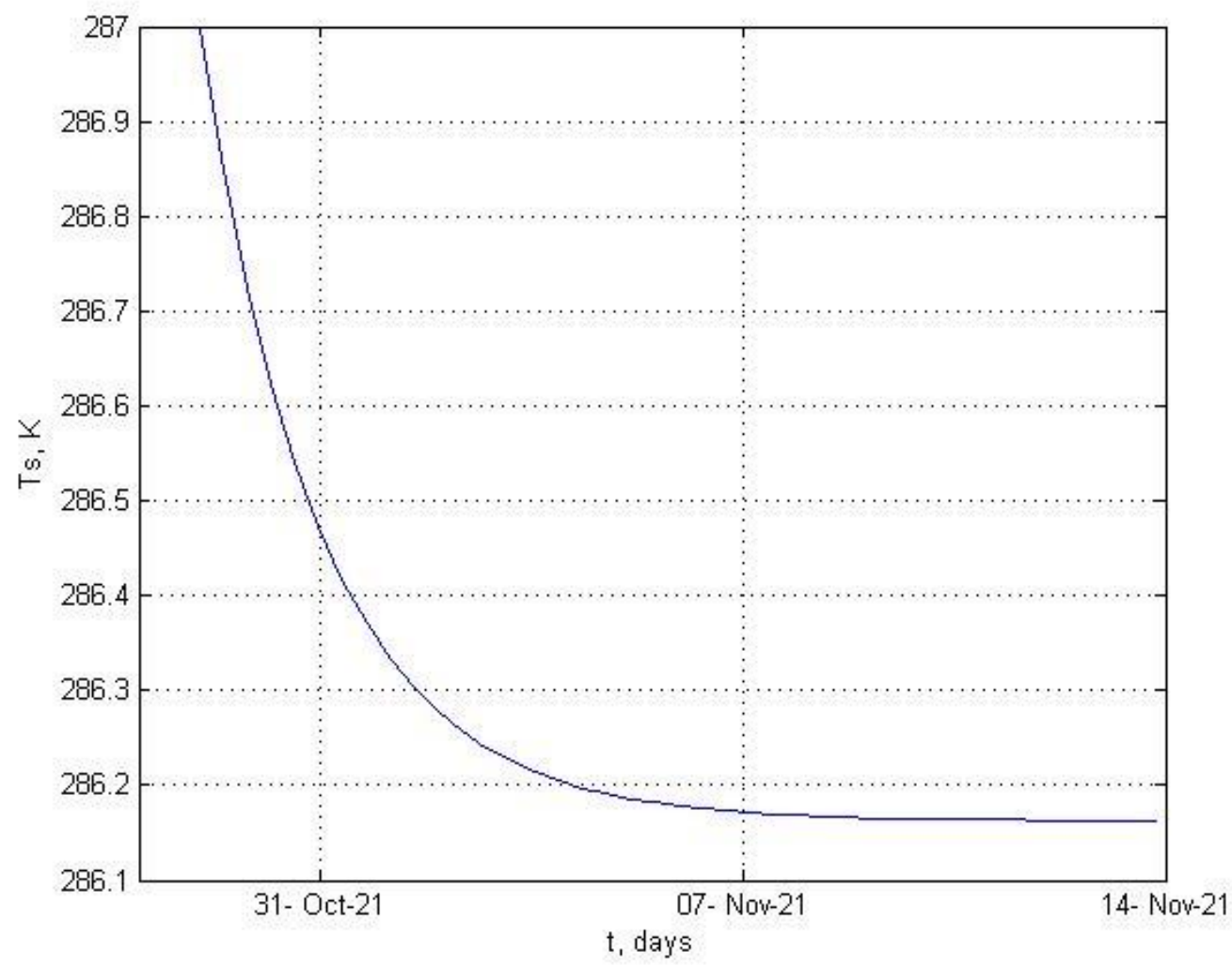

Рис. 2. Динаміка температури поверхні Землі при використанні орбітальних дзеркал

Аналіз одержаних результатів та висновки. Під час виконання роботи проведений аналіз методу управління сонячним випромінюванням 3 використанням орбітальних дзеркал.

Визначено, що для досягнення глобальної середньої температури поверхні Землі доіндустріального рівня потрібно вивести на орбіту дзеркал загальною площею порядку $S_{m}=3.23 \cdot 10^{12} \mathrm{~m}^{2}$.

Обчислений час, за який температура поверхні Землі стає врівноваженою після початку дії орбітальних дзеркал. Даний час становить приблизно 15 діб i досить незначний порівняно із часом розміщення на орбіті всіх необхідних дзеркал.

Подальші дослідження можуть бути проведені у напрямку аналізу можливого використання даного методу управління сонячним випромінюванням у взаємодії із іншими методами зниження глобальної температури Землі.

\section{Бібліографічні посилання}

1. IPCC, 2018: Global warming of $1.5^{\circ} \mathrm{C}$. An IPCC Special Report on the impacts of global warming of $1.5^{\circ} \mathrm{C}$ above pre-industrial levels and related global greenhouse gas emission pathways, in the context of strengthening the global response to the threat of climate change, sustainable development, and efforts to eradicate poverty [V. Masson-Delmotte, P. Zhai, H. O. Pörtner, D. Roberts, J. Skea, P.R. Shukla, A. Pirani, W. Moufouma-Okia, C. Péan, R. Pidcock, S. Connors, J. B. R. Matthews, Y. Chen, X. Zhou, M. I. Gomis, E. Lonnoy, T. Maycock, M. Tignor, T. Waterfield (eds.)]. In Press. 
2. "Net Zero by 2050. A Roadmap for the Global Energy Sector", International Energy Agency, Revised version, October 2021 (4th revision), Information notice found at: www.iea.org/corrections.

3. Eastham, S.,Doherty, S.,Keith, D.,Richter, J. H., Xia, L. Improving models for solar climate intervention research. Eos. 102. https://doi.org/10.1029/2021EO156087.

4. Geoengineering the climate. Science, governance and uncertainty. RS Policy document 10/09, Issued: September 2009 RS1636. 2009. P. 36.

5. Goosse H., P.Y. Barriat, W. Lefebvre, M.F. Loutre and V. Zunz. Introduction to climate dynamics and climate modeling. Online textbook (2008-2010). Режим доступу: http://www.climate.be/textbook.

6. Jim Walsh, Oberlin College Climate models and differential equations. Joint Meetings. Baltimore. 2014. Режим доступу: http://sigmaa.maa.org/em/USE_Math_2014/WalshODEclimate.pdf.

7. Mann Michael E. Why Global Warming Will Cross a Dangerous Threshold in 2036. Scientific American. 2014. Pp. 78-81.

Надійшла до редколегї 01.07. 2021. 